\title{
Globe
}

Revue internationale d'études québécoises

\section{Au coeur et en marge}

Volume 6, numéro 1, 2003

Le Québec au centre et à la périphérie de la francophonie

URI : https://id.erudit.org/iderudit/1000689ar

DOI : https://doi.org/10.7202/1000689ar

Aller au sommaire du numéro

\section{Éditeur(s)}

Globe, Revue internationale d'études québécoises

ISSN

1481-5869 (imprimé)

1923-8231 (numérique)

Découvrir la revue

Citer ce document

(2003). Au coeur et en marge. Globe, 6(1), 11-11.

https://doi.org/10.7202/1000689ar d'utilisation que vous pouvez consulter en ligne.

https://apropos.erudit.org/fr/usagers/politique-dutilisation/ 


\section{Présentation}

\section{Au cour et en marge}

Dans ce numéro, le premier que nous publions sous la responsabilité d'un chercheur étranger, Rachel Killick propose d'examiner la culture québécoise dans la Francophonie à la fois comme un centre et comme une périphérie.

Dans cette perspective, elle a rassemblé les études de Lise Gauvin sur la comparaison des manifestes dans les littératures francophones; de Najib Redouane sur l'identité des écrivains québécois nés en Haiti; d'Yvette Bénayoun-Szmidt sur la constitution d'un champ littéraire francoontarien distinct du champ littéraire québécois ; de Rosemary Chapman sur les rapports spatiaux conflictuels dans l'œuvre de Gabrielle Roy; de Tony Simons sur la quête identitaire dans le film Léolo ainsi que de Ian Lockerbie sur le débat sur l'aménagement de la langue au Québec.

Le numéro se termine par la publication, en étude libre, d'un article d'Ana Isabel Valero Peña sur le pouvoir de la parole chez les Amérindiens de la Nouvelle-France, ainsi que par les recensions et par une bibliographie de parutions récentes en études québécoises. 